\title{
Determination of zearalenone and its metabolites in endometrial cancer by coupled separation techniques
}

\author{
Renata Gadzala-Kopciuch • Krzysztof Cendrowski • \\ Anna Cesarz $\cdot$ Pawel Kielbasa $\cdot$ Bogusław Buszewski
}

Received: 15 February 2011 /Revised: 9 May 2011 /Accepted: 24 June 2011 / Published online: 13 July 2011

(C) The Author(s) 2011. This article is published with open access at Springerlink.com

\begin{abstract}
This study presents a selective method of isolation of zearalenone (ZON) and its metabolite, $\alpha$ zearalenol $(\alpha-Z O L)$, in neoplastically changed human tissue by accelerated solvent and ultrasonic extractions using a mixture of acetonitrile/water $(84 / 16 \% v / v)$ as the extraction solvent. Extraction effectiveness was determined through the selection of parameters (composition of the solvent mixture, temperature, pressure, number of cycles) with tissue contamination at the level of nanograms per gram. The produced acetonitrile/water extracts were purified, and analytes were enriched in columns packed with homemade molecularly imprinted polymers. Purified extracts were determined by liquid chromatography (LC) coupled with different detection systems (diode array detection - DAD and mass spectrometry - MS) involving the Ascentis RP-Amide as a stationary phase and gradient elution. The combination of UE-MISPE-LC (ultrasonic extraction - molecularly imprinted solid-phase extraction - liquid chromatography) produced high $(R \approx 95-98 \%)$ and repeatable $(\mathrm{RSD}<3 \%)$ recovery values for $\mathrm{ZON}$ and $\alpha$-ZOL.
\end{abstract}

This article was published in the special issue Biomarkers with guest editors Boguslaw Buszewski and Jochen Schubert.

R. Gadzała-Kopciuch $(\bowtie) \cdot$ A. Cesarz $\cdot$ P. Kiełbasa •

B. Buszewski

Department of Environmental Chemistry and Bioanalytics,

Faculty of Chemistry, Nicolaus Copernicus University,

7 Gagarin St,

87100 Toruń, Poland

e-mail: rgadz@chem.uni.torun.pl

K. Cendrowski

Department and Clinic of Obstetrics, Gynecology and Oncology,

II Faculty, Medical University of Warsaw,

8 Kondratowicza St,

02242 Warsaw, Poland
Keywords Zearalenone $\cdot \alpha$-Zearalenol $\cdot$ Molecularly imprinted polymers $\cdot$ Liquid chromatography $\cdot \mathrm{DAD} / \mathrm{MS}$. Endometrial cancer

\section{Introduction}

Zearalenone ( $\mathrm{ZON}$ ), also referred to as $\mathrm{F}-2$ toxin, is an estrogenic mycotoxin produced by selected fungi of the genus Fusarium: Fusarium graminearum, Fusarium culmorum, Fusarium cerealis, Fusarium equiseti, Fusarium crookwellense, and Fusarium semitectum (mostly F. graminearum and F culmorum) [1]. ZON and its metabolites have a toxic effect because their structure and shape resembles that of natural estrogens, such as estradiol, estrone, and estriol [2-5].

ZON metabolism has been studied in pigs [6]. Research results have shown that, in pigs and, probably in humans, $\mathrm{ZON}$ is rapidly absorbed after the ingestion of contaminated food, and it is very quickly metabolized in the intestines and liver [6-8]. ZON is reduced, mainly to $\alpha-\mathrm{ZOL}$, and in smaller quantities to $\beta$-ZOL (Fig. 1), which are then decomposed to $\alpha$-ZAL and $\beta$-ZAL $[5,7,9]$. Hydroxysteroid dehydrogenase (HSD) plays a key role in those transformations. Since $\mathrm{ZON}$ has a very similar structure to estradiol, it becomes a substrate for $3 \alpha-\mathrm{HSD}$ and $3 \beta$-HSD [10]. ZON is metabolized to $\alpha-\mathrm{ZOL}$ with the involvement of $3 \alpha$-HSD and to $\beta$-ZOL with the involvement of $3 \beta$-HSD [11]. Excessive levels of ZON and its metabolites are excreted from the body with urine and bile. Following the ingestion of a single ZON dose of $100 \mathrm{mg}$, its concentrations in urine decreased over time as an indication of ZON's metabolism. Zearalenone and its metabolites demonstrate genotoxic activity which results in DNA replication dis- 
Fig. 1 Sample metabolic pathway of zearalenone [7]

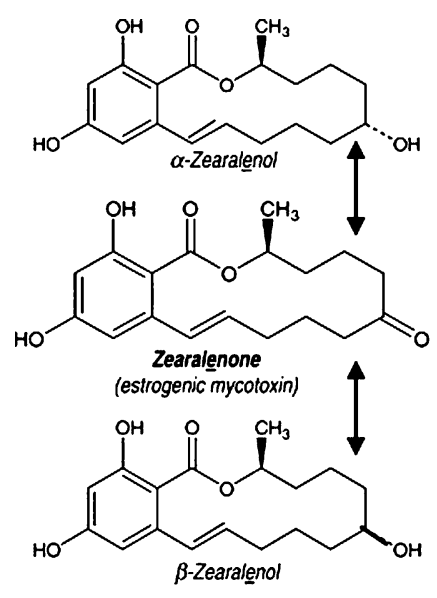

ruptions, chromosomal aberrations (changes in the structure or number of chromosomes), changes in sister chromatids (disruptions during the meiotic or mitotic division of separating chromatids that give rise to new chromosomes), induction of DNA fragmentation (deletion, inversion, duplication, translocation), cell cycle pause, inhibition of protein and DNA synthesis, and apoptosis [3, 11-17]. Every change in the DNA nucleotide sequence leads to mutations. Although some mutations are symptom-free, they exert an effect on the body. There exists a close correlation between mutations and the formation of neoplastic cells. Many mutagens are carcinogens, i.e., factors that contribute to the formation of neoplasms [3, 17-19].

Analyses of toxic and harmful compounds occurring at low concentrations have prompted the search for selective methods of isolating and enriching those compounds from biological matrices, including highly complex matrices such as blood, tissue, and urine at low concentration levels $[15,20]$. An alternative to traditional extraction methods could be posed by solid-phase extraction using selective adsorbents, such as molecularly imprinted polymers (MIP) for isolating and enriching zearalenone and its metabolites, in particular, from complex biological samples. MIPs are increasingly often used as packing for chromatography columns and adsorbents in solid-phase extractions as a relatively cheaper (in comparison with immunosorbents, for example) option that result in higher selectivity than traditional packing [21-27].

This paper investigates the use of molecularly imprinted polymers in purifying extracts and isolating zearalenone and its metabolite, $\alpha$-zearalenol ( $\alpha$-ZOL), in neoplastic endometrial tissue. Scant sources suggest that this mycotoxin may be one of the causes of endometrial cancer. The experimental results of Urraca et al. [21-23] were used to produce a series of polymers with an imprinted cyclododecyl 2,4-dihydroxybenzoate (CDHB) particle, a structural analog of ZON. The physical and chemical characteristics of the synthesized CDHB and molecularly imprinted polymers (nuclear magnetic resonance - NMR, infrared spectroscopy- IR, scanning electron micrographs (SEM)) were determined. $\mathrm{ZON}$ and $\alpha-\mathrm{ZOL}$ were extracted from tissue by accelerated solvent extraction (ASE) and ultrasonic extraction (UE). The obtained extracts were purified by molecularly imprinted solid-phase extraction (MISPE). This type of MIP-CDHB was used for isolating zearalenone and its metabolite and for purifying acetonitrile/water extractions from neoplastic tissue for the first time. Samples were analyzed by liquid chromatography with diode array detection (DAD) and mass spectrometry (MS) with an atmospheric-pressure chemical ionization (APCI) interface.

\section{Materials and methods}

\section{Reagents}

ZON, $\alpha$-ZOL, 2,2'-azobisisobutyronitrile, 1-allyl-piperazine (1-ALPP) (96\%), trimethylolpropane trimethacrylate (TRIM; techn.), cyclododecanol, 1,1'-carbonyldiimidazole ( $\geq 90 \%)$, dimethyl fumarate, 2,4-dihydroxybenzoate acid (97\%), 1,8diazabicyclo[5.4.0]undec-7-ene were purchased from Fluka (Sigma-Aldrich Chemie, Steinheim, Germany). For MISPE and chromatographic analyses, organic solvents of high performance liquid chromatography (HPLC) grade purchased from Baker (Groß-Gerau, Germany) and deionized water (Mili-Q, Millipore, El Paso, TX, USA) were employed. Aluminum oxide (150 mesh) and silica gel (230-400 mesh) for CDHB purification was supplied by Merck (Darmstadt, Germany). Anhydrous sodium sulfate (POCh, Gliwice, Poland) was the drying agent.

Working solutions were prepared by weighing $1.09 \mathrm{mg}$ zearalenone and $1.10 \mathrm{mg} \alpha$-zearalenol and dissolving them in acetonitrile in $10 \mathrm{ml}$ volumetric flasks. The produced solutions had the concentration of $109.0 \mu \mathrm{g} / \mathrm{ml}$ zearalenone and $110.0 \mu \mathrm{g} / \mathrm{ml} \alpha$-zearalenol. Solutions of lower concentrations were produced by diluting the working solutions to obtain concentrations of 0.01 to $3 \mu \mathrm{g} / \mathrm{ml}$ in the mobile phase. 


\section{Equipment}

Liquid chromatography analyses were carried out using an Agilent Technologies 1100 chromatograph with an Ascentis RP-Amide column (Supelco, USA; 250×4.6 mm ID, $5 \mu \mathrm{m}$ particle size) equipped with a DAD, mass spectrometer (MSD Trap VL Agilent), and an autosampler. Data acquisition and quantification were conducted using Agilent ChemStation software. The column was kept in an oven (Gynkotek, Germering, Germany) at a temperature of $21.0{ }^{\circ} \mathrm{C} \pm 0.1$. Chromatographic separations were performed using a gradient elution with acetonitrile $(\mathrm{A})$ and water $(\mathrm{B})-0-5 \mathrm{~min}, 50 \%$ A; 5-25 min 50-100\% A; 35 min 100\% A; 35-45 min 100$50 \% \mathrm{~A}$; and $55 \mathrm{~min} 50 \% \mathrm{~A}$. The flow rate was $1 \mathrm{ml} / \mathrm{min}$; column temperature was kept at $21{ }^{\circ} \mathrm{C}$, and analytical wavelength was set at $\lambda=270 \mathrm{~nm}$. Injection volume was
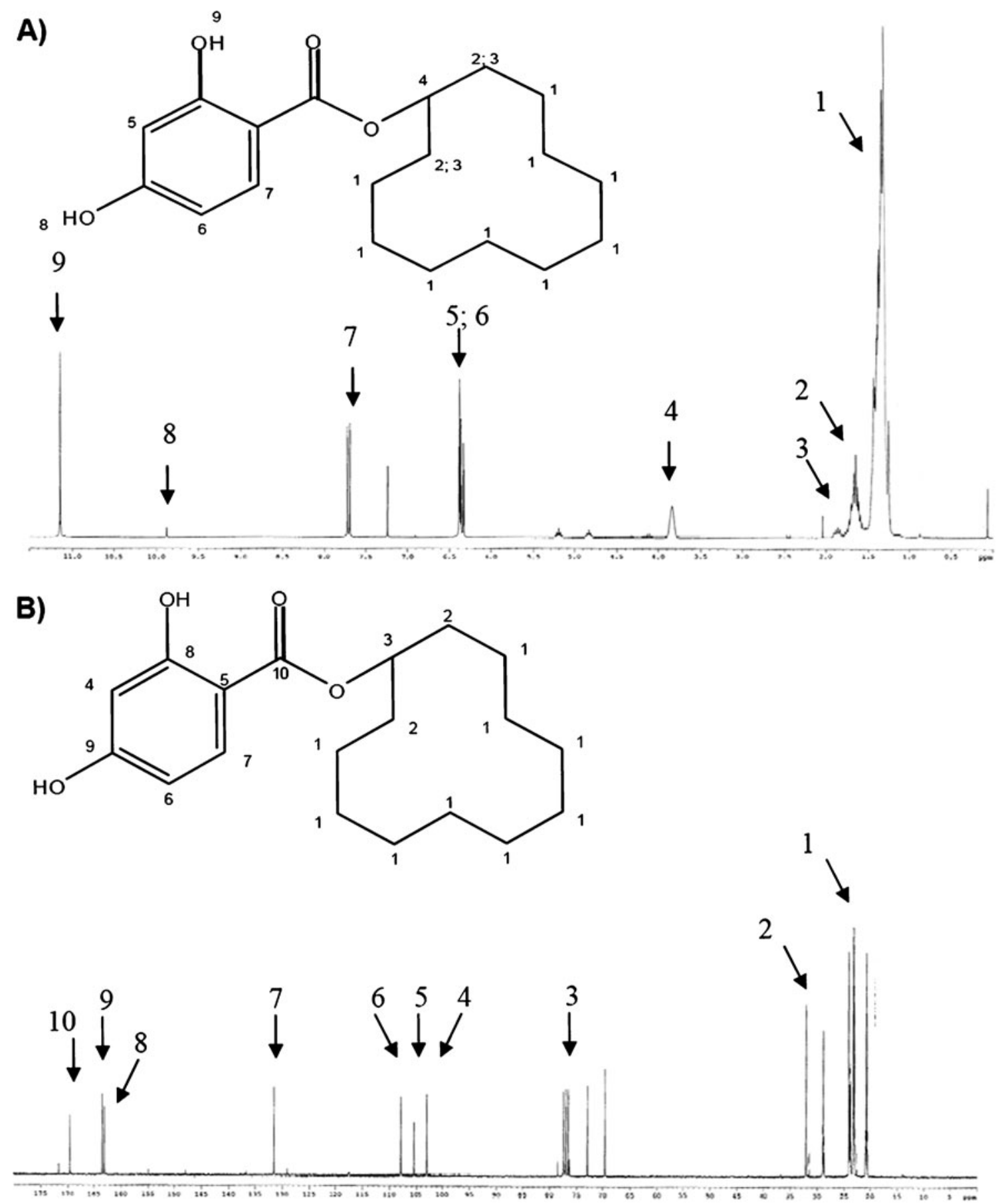

Fig. $2{ }^{1} \mathrm{H}$ NMR (a) and ${ }^{13} \mathrm{C}$ NMR (b) spectra for cyclododecyl 2,4-dihydroxybenzoate 
Fig. 3 Structure of 1-ALPP and CDHB molecules and the probable location of hydrogen bonds between the template and monomer molecules
A)

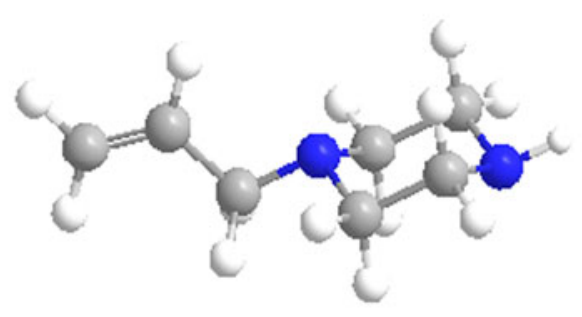

1-ALPP

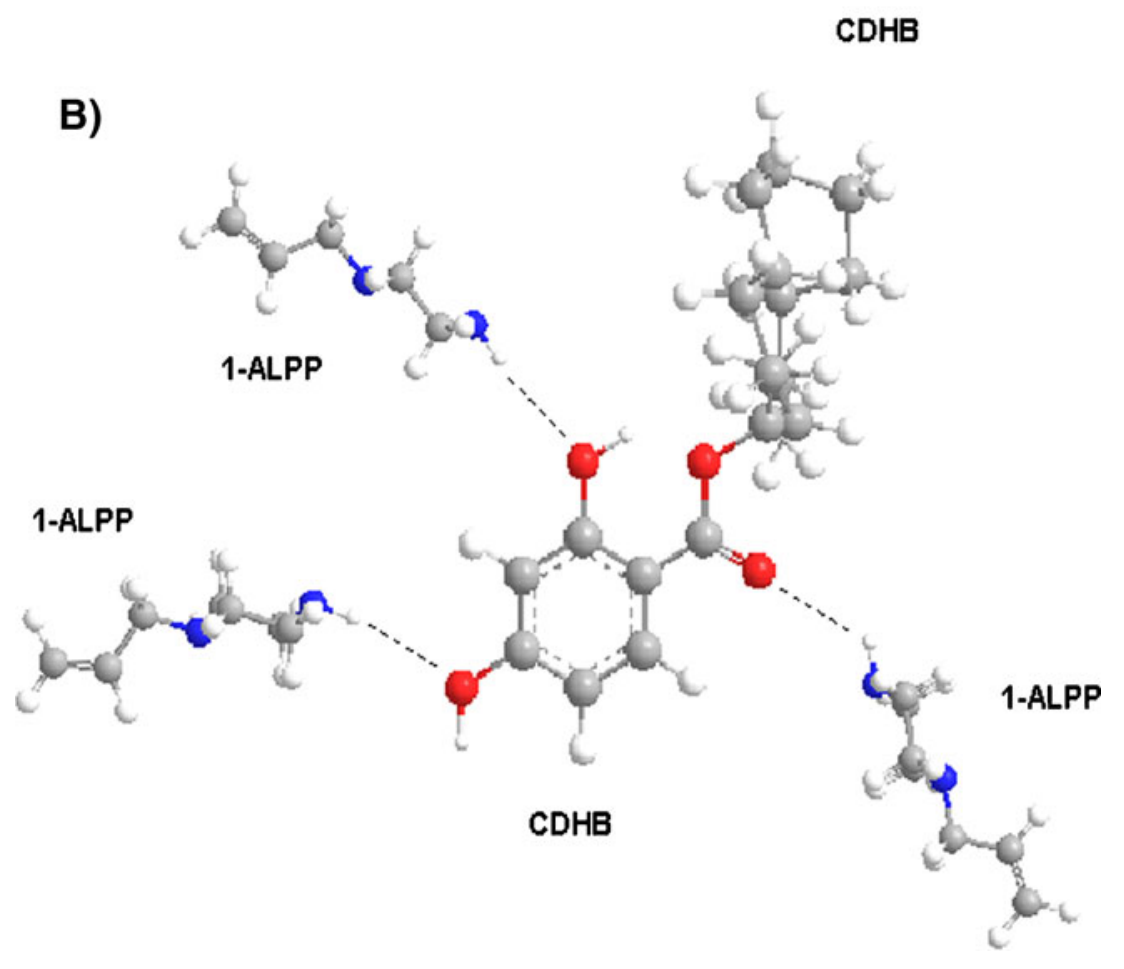

$10 \mu$ l. The mass spectrometer was equipped with an APCI source. The following APCI conditions were applied: ionizing gas (nitrogen), $60 \mathrm{psi}$; flow, $7.5 \mathrm{ml} / \mathrm{min}$; auxiliary gas (helium), $10 \mathrm{psi}$; ion source temperature, $278{ }^{\circ} \mathrm{C}$; gas

Fig. 4 Scanning electron micrographs of non-imprinted (a) and imprinted (b) polymer (MIP-CDHB)
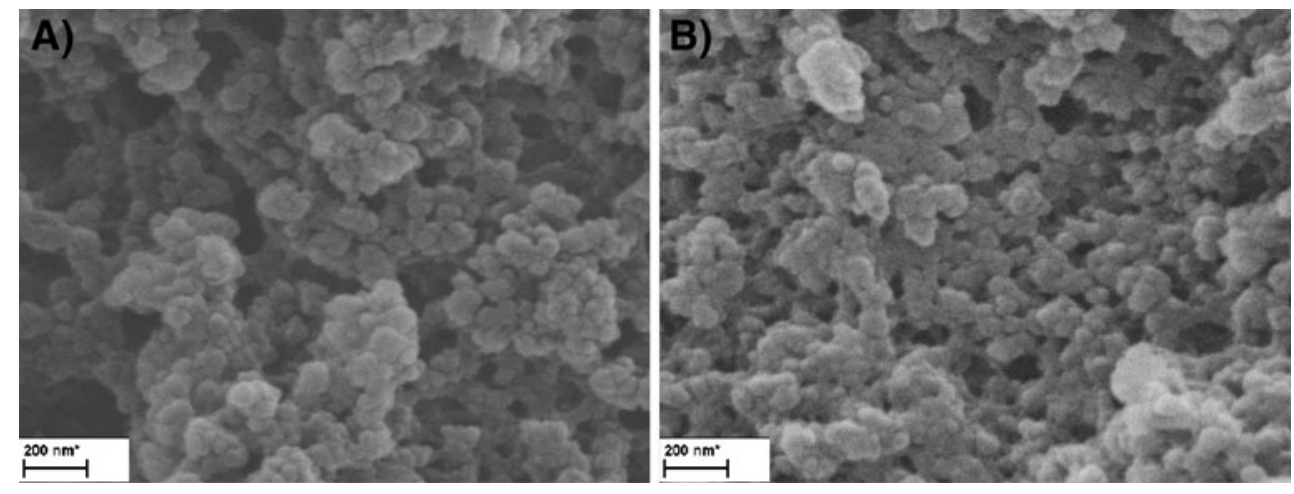
drying temperature, $320{ }^{\circ} \mathrm{C}$; and corona current, $3,000 \mathrm{nA}$. The mass spectra of the analyzed xenoestrogens were within the scanning range of $300-350 \mathrm{~m} / \mathrm{z}$ in the negative ionization option at capillary voltage $4.0 \mathrm{~V}$.

${ }^{1} \mathrm{H}$ and ${ }^{13} \mathrm{C}$ NMR spectra were recorded with Bruker 300 MSL (Rhenstteten, Germany) spectrometer at 300 and $75 \mathrm{MHz}$, respectively. Infrared spectroscopy results were obtained on Perkin-Elmer 1800 (Norwalk, CT, USA) infrared spectrophotometer. Melting points were obtained with a Fischer Johns melting point apparatus. The porosity and surface area of the developed micro/nanospheres and bulk polymers were determined by nitrogen adsorption/ desorption analysis using a nitrogen surface area analyzer (ASAP 2012, Micromeritics Instrument Corp., USA). SEM results were obtained using Leo 1430 VP apparatus (Leo, Electronenmikroskopie, GmbH, Oberkochen, Germany).

Solid-phase extraction was performed using a 12-port vacuum manifold supplied by Mallinckrodt Baker (Deventer, The Netherlands). MISPE columns were prepared using solid-phase extraction (SPE) glass columns (volume of $1 \mathrm{ml}$ ) equipped with porous polytetrafluoroethylene (PTFE) disks (Mallinckrodt Baker) at the top and at the bottom of the polymer bed. Soxhlet extractions were carried out using an extractor supplied by Agat (Szczecin, Poland).

Synthesis of cyclododecyl 2,4-dihydroxybenzoate

The synthesis of the ZON-mimic template, cyclododecanyl2,4-dihydroxybenzoate, has been described by Urraca et al. $[21,23]$. For the purpose of obtaining pure cyclododecyl 2,4-dihydroxybenzoate, its synthesis was modified by annealing silica gel at $120^{\circ} \mathrm{C}$ for $24 \mathrm{~h}$ until the purification stage. Elution was carried out using an $n$-hexane: octane ethyl mixture $(60: 40 \% v / v)$. The product was crystallized and dried in a vacuum drier, producing a white solid substance with melting point in the range of $57.5^{\circ} \mathrm{C}$ to $61^{\circ} \mathrm{C}$.
Nuclear magnetic resonance was performed for ${ }^{1} \mathrm{H}$ and ${ }^{13} \mathrm{C}$ to verify the product's structure. Deuterated chloroform was applied as the solvent, and trimethylsilane was the reference standard (Fig. 2a, b).

The IR spectrum was obtained by preparing a $\mathrm{KBr}$ sample. It was used to determine vibrational frequency $\nu$ : 3,487 ; 3,$161 ; 3,933 ; 1,656 ; 1,469 ; 1,253 ; 852 ;$ and $779 \mathrm{~cm}^{-1}$.

\section{Polymer synthesis}

Two types of polymers were prepared simultaneously. In the first polymer, $1 \mathrm{mmol}$ cyclododecyl 2,4-dihydroxybenzoate (MIP) was used as the template, while the second polymer was prepared without a template to produce a non-imprint polymer (NIP). The initiator in the synthesis of both polymers was $2,2^{\prime}$-azobis(isobutynitrile) $(0.47 \mathrm{mmol})$. 1Allyl-piperazine $(4 \mathrm{mmol})$ was the functional monometer; TRIM $(20 \mathrm{mmol})$ was the cross-linking monomer, and acetonitrile was the pore-forming solvent [22, 23]. The monomer to pore-forming solvent volume ratio was 40:60. Polymerization was carried out twice in tight vials of 15 and $2 \mathrm{ml}$. Polymerization mixtures were degassed in an ultrasound bath and rinsed with nitrogen for $30 \mathrm{~min}$. Vials were placed in a chamber with a thermostat-controlled water bath $\left(4{ }^{\circ} \mathrm{C}\right)$ and a UV lamp $(\lambda=365 \mathrm{~nm})$. Photopolymerization was carried out for $1.5 \mathrm{~h}$. The probable location of hydrogen bonds between a CDHB molecule and 1-ALPP molecules is shown in Fig. 3. Polymers were disintegrated; the template and non-reacted substrates were extracted with a methanol and acetic acid mixture (96:4\% $v / v)$ in a Soxhlet apparatus over $24 \mathrm{~h}$, because ASE did not fully remove the template. Non-imprinted polymers were prepared following the same procedure but in the absence of template molecule. Structural variations in the surface morphology and internal structure of the both MIP and NIP polymer particles resulting were studied by the SEM
Table 1 Selection of parameters for ASE isolation of ZON and its metabolite

\begin{tabular}{|c|c|c|c|c|c|}
\hline No. & Tissue & $\begin{array}{l}\text { Solvent or } \\
\text { combination of } \\
\text { solvents, } \% v / v\end{array}$ & $\begin{array}{l}\text { Quantity of used } \\
\text { mixture, ml }\end{array}$ & $\begin{array}{l}\text { Number of } \\
\text { extraction } \\
\text { cycles }\end{array}$ & Temperature, ${ }^{\circ} \mathrm{C}$ \\
\hline 1 & \multirow{4}{*}{$\begin{array}{l}\text { Veal muscle } \\
\text { tissue }\end{array}$} & $\mathrm{MeOH}$ & \multirow[t]{3}{*}{42} & \multirow[t]{3}{*}{2} & \multirow[t]{8}{*}{110} \\
\hline 2 & & $\mathrm{ACN} / \mathrm{H}_{2} \mathrm{O} 84: 16$ & & & \\
\hline 3 & & ACN/MeOH 84:16 & & & \\
\hline 4 & & ACN/MeOH 84:16 & 44 & 4 & \\
\hline 5 & \multirow{4}{*}{$\begin{array}{l}\text { Poultry muscle } \\
\text { tissue }\end{array}$} & ACN/MeOH 84:16 & & & \\
\hline 6 & & ACN/MeOH 84:16 & & & \\
\hline 7 & & ACN/MeOH 84:16 & 46 & & \\
\hline 8 & & $\mathrm{ACN} / \mathrm{H}_{2} \mathrm{O} 84: 16$ & 46 & & \\
\hline 9 & \multirow[t]{4}{*}{ Poultry liver } & $\mathrm{ACN} / \mathrm{H}_{2} \mathrm{O} 84: 16$ & 52 & & 150 \\
\hline 10 & & $\mathrm{ACN} / \mathrm{H}_{2} \mathrm{O} 84: 16$ & 64 & & 200 \\
\hline 11 & & Chloroform & 43 & & 110 \\
\hline 12 & & $\mathrm{ACN}$ & 42 & 2 & 110 \\
\hline
\end{tabular}


Table 2 Recovery of ZON and $\alpha-\mathrm{ZOL}$ isolated from animal liver by UE and MIP-CDHB purification

${ }^{\mathrm{a}} \mathrm{RSD}$, standard deviation $(n=4)$

\begin{tabular}{|c|c|c|c|c|c|}
\hline \multirow[t]{2}{*}{ Solvent combination } & \multirow[t]{2}{*}{ Composition, $\% v / v$} & \multicolumn{2}{|l|}{$\alpha-Z O L$} & \multicolumn{2}{|l|}{$\mathrm{ZON}$} \\
\hline & & Recovery, \% & $\mathrm{RSD}^{\mathrm{a}}, \%$ & Recovery, \% & $\mathrm{RSD}^{\mathrm{a}}, \%$ \\
\hline $\mathrm{ACN} / \mathrm{H}_{2} \mathrm{O}$ & $50: 50$ & 90.5 & 2.0 & 85.3 & 0.3 \\
\hline $\mathrm{ACN} / \mathrm{H}_{2} \mathrm{O}$ & $84: 16$ & 97.9 & 1.6 & 95.4 & 1.8 \\
\hline $\mathrm{MeOH} / \mathrm{H}_{2} \mathrm{O}$ & $80: 20$ & 89.0 & 0.2 & 82.5 & 1.2 \\
\hline $\mathrm{ACN} / \mathrm{MeOH}$ & $50: 50$ & 88.7 & 0.8 & 91.3 & 0.1 \\
\hline $\mathrm{ACN} / \mathrm{MeOH}$ & $84: 16$ & 92.7 & 2.1 & 94.9 & 1.8 \\
\hline
\end{tabular}

microscope (Fig. 4). The SEM microscopic technique confirmed that the application of acetonitrile gave rise to a higher number of specific interactions between CDHB template and monomers (1-ALPP), resulting in compact and more porous morphology of the imprinted polymers. CDHB binding with 1-ALPP during MIP synthesis produced larger globules and pores in comparison with NIP molecular imprinting without template. The non-imprinted polymer had very small surface globules.

The polymer was dried in a vacuum drier at $50{ }^{\circ} \mathrm{C}$ for $24 \mathrm{~h}$, producing polymers with a specific surface area of $248 \mathrm{~m}^{2} / \mathrm{g}$ and a pore volume of $0.46 \mathrm{~cm}^{3} / \mathrm{g}$. The dried product was disintegrated in a mortar and fractioned with the use of mesh sieves. The obtained fractions had grain size of 45 to $63 \mu \mathrm{m}$, and they were used to fill SPE columns.

\section{Sample preparation}

Samples of uterus tissue were collected from seven women with endometrial cancer aged 66-76 years during a surgical procedure. Directly after collection, samples were placed in a

Table 3 Results of extractions performed in the ASE apparatus after MISPE clean-up and preconcentration

\begin{tabular}{lll}
\hline No. $^{a}$ & \multicolumn{2}{l}{ Recovery $( \pm$ RSD $), \%$} \\
\cline { 2 - 3 } & ZON & $\alpha-$ ZOL \\
\hline 1 & $19.8( \pm 3.2)$ & $22.4( \pm 2.4)$ \\
2 & $61.1( \pm 1.7)$ & $61.5( \pm 1.3)$ \\
3 & $60.6( \pm 2.5)$ & $65.3( \pm 1.7)$ \\
4 & $69.0( \pm 1.1)$ & $63.3( \pm 0.8)$ \\
5 & $79.5( \pm 0.8)$ & $79.9( \pm 1.4)$ \\
6 & $69.3( \pm 1.6)$ & $62.7( \pm 1.3)$ \\
7 & $70.0( \pm 0.5)$ & $76.9( \pm 1.0)$ \\
8 & $70.9( \pm 1.2)$ & $71.1( \pm 2.6)$ \\
9 & $79.5( \pm 1.0)$ & $80.7( \pm 1.1)$ \\
10 & $89.8( \pm 0.6)$ & $90.1( \pm 0.9)$ \\
11 & $52.1( \pm 2.9)$ & $53.4( \pm 2.3)$ \\
12 & $28.4( \pm 3.1)$ & $37.6( \pm 2.8)$ \\
\hline
\end{tabular}

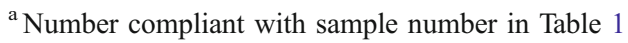

dark container and frozen in liquid nitrogen. In view of the small quantity and weight of the collected samples, veal and poultry muscle tissue and poultry liver, whose consistency was most similar to neoplastic tissue, were used to investigate extraction and purification effectiveness. Animal tissue samples were freeze-stored. Frozen animal tissue was disintegrated and analytical samples of $0.5,1,1.5$, and $2 \mathrm{~g}$ were prepared. Tissue was contaminated with $100 \mu \mathrm{l}$ standard solution of zearalenone and $\alpha$-zearalenol, each with the estimated concentration of $10 \mu \mathrm{g} / \mathrm{ml}$. They were subjected to UE and ASE by applying different extraction conditions, solvents, and solvent combinations (Tables 1 and 2).

In the ultrasonic extraction, each sample was twice extracted using a mixture of acetonitrile $(\mathrm{ACN}) / \mathrm{H}_{2} \mathrm{O}$ $(84: 16 \% v / v), \mathrm{ACN} / \mathrm{MeOH}(50: 50 \% v / v), \quad \mathrm{ACN} / \mathrm{H}_{2} \mathrm{O}$ $(50: 50 \% v / v), \mathrm{ACN} / \mathrm{MeOH}(84: 16 \% v / v)$, and $\mathrm{MeOH} / \mathrm{H}_{2} \mathrm{O}$ $(80: 20 \% \mathrm{v} / \mathrm{v})$ of $15 \mathrm{ml}$ each. When $15 \mathrm{ml}$ of the solvent mixture was added, samples were ultrasonically homogenized ( $5 \mathrm{~min}$, five cycles, $100 \%$ power). The supernatant was centrifuged for $12 \mathrm{~min}(3,500 \mathrm{rpm})$.

In ASE (extractor ASE 100, Dionex), each sample was extracted with different solvents and temperatures (Table 1)

Table 4 The effect of polymer quantity on recovery values

\begin{tabular}{|c|c|c|c|c|}
\hline \multirow{2}{*}{$\begin{array}{l}\text { Polymer quantity } \\
{[\mathrm{mg}]}\end{array}$} & \multicolumn{2}{|l|}{$\mathrm{ZON}$} & \multicolumn{2}{|l|}{$\alpha-Z O L$} \\
\hline & $\begin{array}{l}\text { Recovery, } \\
\%\end{array}$ & $\begin{array}{l}\text { RSD, } \\
\%\end{array}$ & $\begin{array}{l}\text { Recovery, } \\
\%\end{array}$ & $\begin{array}{l}\mathrm{RSD}, \\
\%\end{array}$ \\
\hline \multicolumn{5}{|c|}{ Solvent: $\mathrm{ACN} / \mathrm{H}_{2} \mathrm{O} 84: 16$} \\
\hline 50 & 49.4 & 2.0 & 59.3 & 1.6 \\
\hline 100 & 60.7 & 1.8 & 66.7 & 2.1 \\
\hline 150 & 68.9 & 1.7 & 80.2 & 2.2 \\
\hline 200 & 97.9 & 0.9 & 95.4 & 1.4 \\
\hline 250 & 97.2 & 2.1 & 95.0 & 1.9 \\
\hline \multicolumn{5}{|c|}{ Solvent: ACN/MeOH 84:16 } \\
\hline 50 & 41.5 & 1.7 & 42.1 & 2.3 \\
\hline 100 & 51.5 & 0.9 & 57.0 & 1.4 \\
\hline 150 & 65.5 & 1.6 & 68.7 & 2.0 \\
\hline 200 & 92.7 & 2.1 & 94.9 & 1.8 \\
\hline 250 & 92.1 & 2.3 & 93.9 & 2.0 \\
\hline
\end{tabular}


Table 5 Limit of detection and quantification obtained for ZON and $\alpha-Z O L$ analysis in tissue samples (animal liver) using UE-MISPE and LC-DAD analysis

\begin{tabular}{lcccc}
\hline Compound & LOD, ng/g & SD & LOQ, ng/g & SD \\
\hline ZEA & 8.10 & 0.27 & 24.30 & 0.10 \\
$\alpha$-ZOL & 14.02 & 0.28 & 42.06 & 0.14 \\
\hline
\end{tabular}

$L O D$ limit of detection, $L O Q$ limit of quantification

under pressure of $1,500 \mathrm{psi}$. A total of five static cycles were used at $5 \mathrm{~min}$ per cycle, with a final flush of solvent equal to $75 \%$ of the cell volume (approx. $11 \mathrm{~mL}$ ).

UE- and ASE-derived extracts were evaporated to $2 \mathrm{ml}$ and diluted with water at the 1:5 ratio. The filtered supernatant was transferred to MIP-CDHB columns conditioned with $5 \mathrm{ml}$ methanol and $5 \mathrm{ml}$ redistilled water. After application, the polymer was rinsed with $5 \mathrm{ml}$ redistilled water. The sorbent was dried, and the adsorbed analytes were eluted with the solvent.

\section{Results and discussion}

Optimization of the ASE and UE method for ZON and $\alpha-\mathrm{ZOL}$

Due to the absence of documented experiments aiming to isolate selected analytes from human tissue and very few studies investigating animal tissue, mixtures of solvents with various compositions were used as extractants for ASE (Table 1) and UE (Table 2). In view of the complexity of biological matrices, the isolation procedure and the sample purification process required a solvent capable of removing proteins and fats.

The recovery values for both analytes after UE-MIPCDHB with the use of various solvent combinations (methanol/water, acetonitrile/water) and different volume ratios were within the range of $82.5-97.9 \%$. The best results were noted for the $\mathrm{ACN} / \mathrm{H}_{2} \mathrm{O}$ mixture at the volume ratio of $84: 16 \% v / v$ where $\alpha$-ZOL recovery reached $97.9 \%$ and ZON recovery, $-95.4 \%$. Low standard deviation values of $0.2-2.1 \%$ testify to the high repeatability of isolation and purification of tissue supernatants with the use of CDHB-imprinted polymers which are selective sorbents.

Tissue supernatants produced with the use of solvents specified in Table 2 were deproteinized and degreased with hexane. Low recovery values were obtained for both compounds (ZON and $\alpha$-ZOL) at $5.49 \% \pm 2.6 \%$ and $4.94 \% \pm 2.2 \%$, respectively. Excessive acetonitrile concentrations in the sample applied to fill the column lowered the analyte's reaction with the polymer. For this reason, acetonitrile/water extracts $(84: 16 \% \mathrm{v} / \mathrm{v})$ from acetonitrile/ water extract tissue $(84: 16 \% v / v)$ were diluted with water at the 1:5 ratio without hexane degreasing, and they were applied to the conditioned MIP-CDHB polymer bed. Recovery reached $95-97 \%$, indicating that sample deproteinization and degreasing were redundant.

Similar results were noted in accelerated solvent extraction (Table 3). The recovery values reported for extracts with the use of the $84: 16 \% v / v \mathrm{ACN} /$ water mixture were the highest for poultry liver and poultry muscle tissue $(62-90 \%)$. Similarly to temperature growth, an increase in the number of extraction cycles contributes to higher recovery values $\left(5\right.$ cycles, $200{ }^{\circ} \mathrm{C}$, $64 \mathrm{ml})$. The highest recovery values for zearalenone $(89.8 \%)$ and for $\alpha$-zearalenol $(90.1 \%)$ were reported for four extraction cycles with a combination of $\mathrm{ACN} / \mathrm{H}_{2} \mathrm{O}(84: 16 \% v / v)$ solvents at a temperature of $200{ }^{\circ} \mathrm{C}$. The use of pure solvents, i.e., acetonitrile, methanol, and chloroform, did not bring satisfactory results. Recovery values were significantly lower (more than $50 \%$ ) compared with those obtained with the use of the above solvent mixtures (Table 3).

When non-imprint polymers (NIP) were used, recovery values for both ZON and $\alpha$-ZOL dropped by $40 \%$ in comparison with MIP-CDHB. The repeated use of the NIP column led to an increase in the intensity of peaks generated by the coexisting compounds. An increase in the quantity of the above polymer had no significant effect on extract purification.

The effect of polymer quantity on recovery values

In both extraction methods (UE and ASE) used to isolate $\mathrm{ZON}$ and $\alpha-\mathrm{ZOL}$, the most satisfactory results were reported in respect of $\mathrm{ACN} / \mathrm{H}_{2} \mathrm{O}(84: 16 \% v / v)$ and $\mathrm{ACN} /$ $\mathrm{MeOH}(84: 16 \% v / v)$, and the above mixtures were taken into account during the selection of extraction parameters
Table 6 Extraction recoveries (and RSDs) obtained from blank tissue spiked (animal liver) at different concentration levels of ZON and $\alpha$-ZOL using ultrasonic extraction, MIP-CDHB purification and chromatographic analysis, LC-DAD $(n=3)$

\begin{tabular}{ccccc}
\hline Spiked level, $\mu \mathrm{g} / \mathrm{g}$ & Recovery of ZON, \% & RSD, \% & Recovery of $\alpha$-ZOL, \% & RSD, \% \\
\hline 0.05 & 98.4 & 3.6 & 96.9 & 4.1 \\
0.10 & 98.1 & 1.7 & 95.8 & 1.8 \\
0.25 & 97.9 & 1.5 & 96.2 & 1.4 \\
0.50 & 96.5 & 2.5 & 93.8 & 2.4 \\
2.00 & 94.6 & 3.1 & 92.2 & 3.5 \\
\hline
\end{tabular}


Table 7 The content of zearalenone and $\alpha$-zearalenol in the body of the uterus

\begin{tabular}{|c|c|c|c|c|}
\hline $\begin{array}{l}\text { Patient } \\
\text { no. }\end{array}$ & $\begin{array}{l}\text { Patient's } \\
\text { age }\end{array}$ & Type of neoplasm & $\begin{array}{l}\alpha \text {-Zearalenol content, } \\
\mu \mathrm{g} / \mathrm{g} \text { tissue }\end{array}$ & $\begin{array}{l}\text { Zearalenone content, } \\
\mu \mathrm{g} / \mathrm{g} \text { tissue }\end{array}$ \\
\hline 1 & 75 & $\begin{array}{l}\text { Endometrial cancer, grade III; histopathological examination: ovarian } \\
\text { adenocarcinoma }\end{array}$ & 0.7831 & 0.1474 \\
\hline 2 & 66 & $\begin{array}{l}\text { Endometrial cancer, grade I; histopathological examination: endometrial } \\
\text { adenocarcinoma }\end{array}$ & 0.4501 & - \\
\hline 3 & 71 & $\begin{array}{l}\text { Endometrial cancer, grade 0; histopathological examination: complex } \\
\text { mucosal hyperplasia }\end{array}$ & 0.1301 & - \\
\hline 4 & 70 & $\begin{array}{l}\text { Endometrial cancer, grade III; histopathological examination: uterine } \\
\text { sarcoma with parametrial infiltration }\end{array}$ & 0.9644 & - \\
\hline 5 & 76 & $\begin{array}{l}\text { Endometrial cancer, grade } 0 \text {; histopathological examination: complex } \\
\text { mucosal hyperplasia }\end{array}$ & 1.6968 & 0.2865 \\
\hline 6 & 68 & $\begin{array}{l}\text { Endometrial cancer, grade III; histopathological examination: } \\
\text { undifferentiated serous carcinoma }\end{array}$ & 0.3188 & - \\
\hline 7 & 66 & $\begin{array}{l}\text { Endometrial cancer, grade I; histopathological examination: endometrial } \\
\text { adenocarcinoma }\end{array}$ & 0.9477 & 0.1384 \\
\hline
\end{tabular}

in the MISPE analysis. To verify adsorption and desorption effectiveness, glass SPE columns were packed with the same polymer in increasing quantities from 50 to $250 \mathrm{mg}$. Tissue extracts containing zearalenone and $\alpha$ zearalenol in concentrations of 109 and $110 \mathrm{ng} / \mathrm{g}$, respectively, were applied to each column. The results are presented in Table 4.

For the purpose of verifying the effectiveness of zearalenone and $\alpha$-zearalenol desorption with MIP$\mathrm{CDHB}$, various volumes of acetonitrile were applied as the solvent. The highest recovery values were reported for $4 \mathrm{ml}$, reaching $97.9 \%$ for zearalenone $( \pm 0.8 \%)$ and $95.4 \%$ for $\alpha$-zearalenol $( \pm 1.4 \%)$. Standard deviation was below $1.5 \%$, and the above quantity was regarded as optimal for effective desorption. The highest recovery values in excess of $90 \%$ were noted in columns packed with 200 and $250 \mathrm{mg}$ MID-CDHB for both solvent combinations.

In view of repeatable (RSD below $2 \%$ ) and high recovery values, ZON and $\alpha$-ZOL were extracted from neoplastic tissue by the ultrasound-assisted method with the involvement of $\mathrm{ACN} / \mathrm{H}_{2} \mathrm{O}(84: 16 \% v / v)$ and purified using 200 mg MIP-CDHB.

Performance of the analytical method

The applied method was validated based on the following parameters: linearity, selectivity, precision (repeatability), measurement uncertainty, and accuracy. Calibration curves were determined for the tissue extract (UEMISPE), which were linear in the range of concentrations from 0.054 to $10.9 \mu \mathrm{g} / \mathrm{ml}$ for ZON $(y=43.252 x+$ $1.3316)$ and 0.055 to $11.0 \mu \mathrm{g} / \mathrm{ml}$ for $\alpha-Z O L(y=34.28 x+$ $0.7014)$. Linearity was satisfactory in both cases, as demonstrated by high regression coefficients $(r=0.9999$ for ZON; $r=0.9998$ for $\alpha-\mathrm{ZOL}$ ). The limit of detection for tissue extracts was computed at the signal-to-noise ratio of
3:1, and the limit of quantification — at the signal-to-noise ratio of 10:1 (Table 5). The values reported for liquid chromatography-diode array detection (LC-DAD) are insignificantly higher in comparison with fluorescent detection $[21,23]$, therefore mass spectrometry was used to confirm analyte identity.

Coefficients of variation (RSD, \%) were used to determine assay precision. RDS values, expressed as the percentage arithmetic mean (Table 6), were below $4.1 \%$ and can be considered satisfactory.

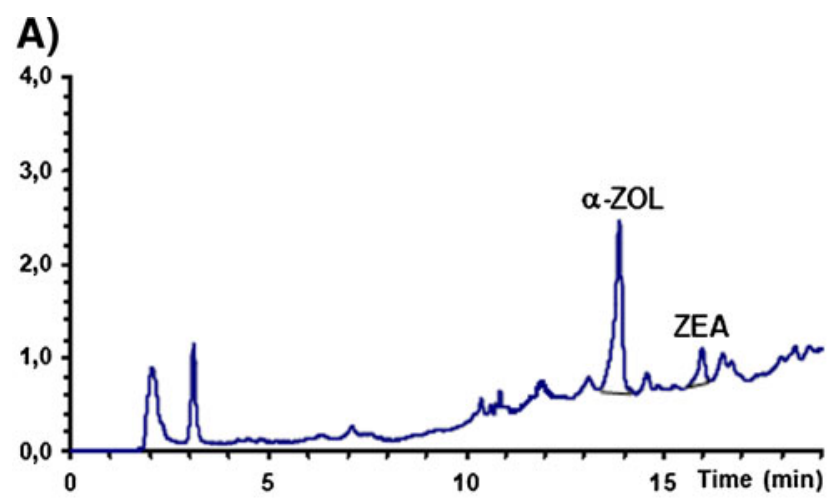

B)

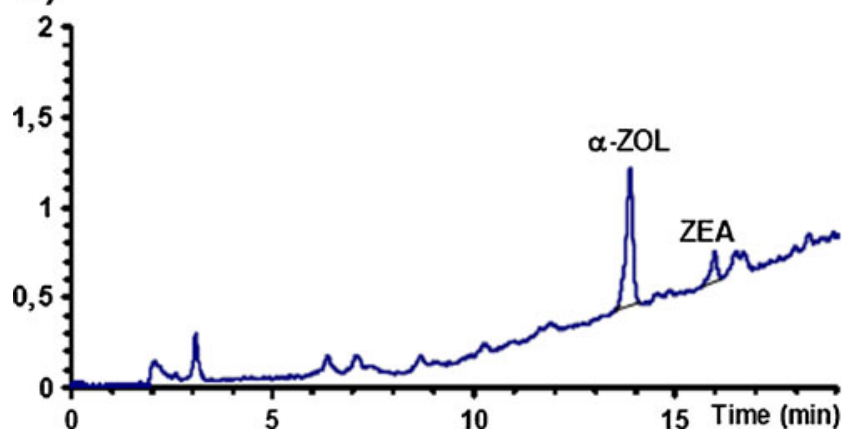

Fig 5 Chromatograms of extracts of neoplastically changed tissue samples from the uterine body of patients no. 5 (a) and no. 7 (b) 
Fig. 6 Mass spectra for $\mathrm{ZON}$ $(\mathrm{m} / \mathrm{z}=319.0, \mathbf{a})$ and $\alpha$-ZOL $(\mathrm{m} / \mathrm{z}$ $=317.1, \mathbf{b})$
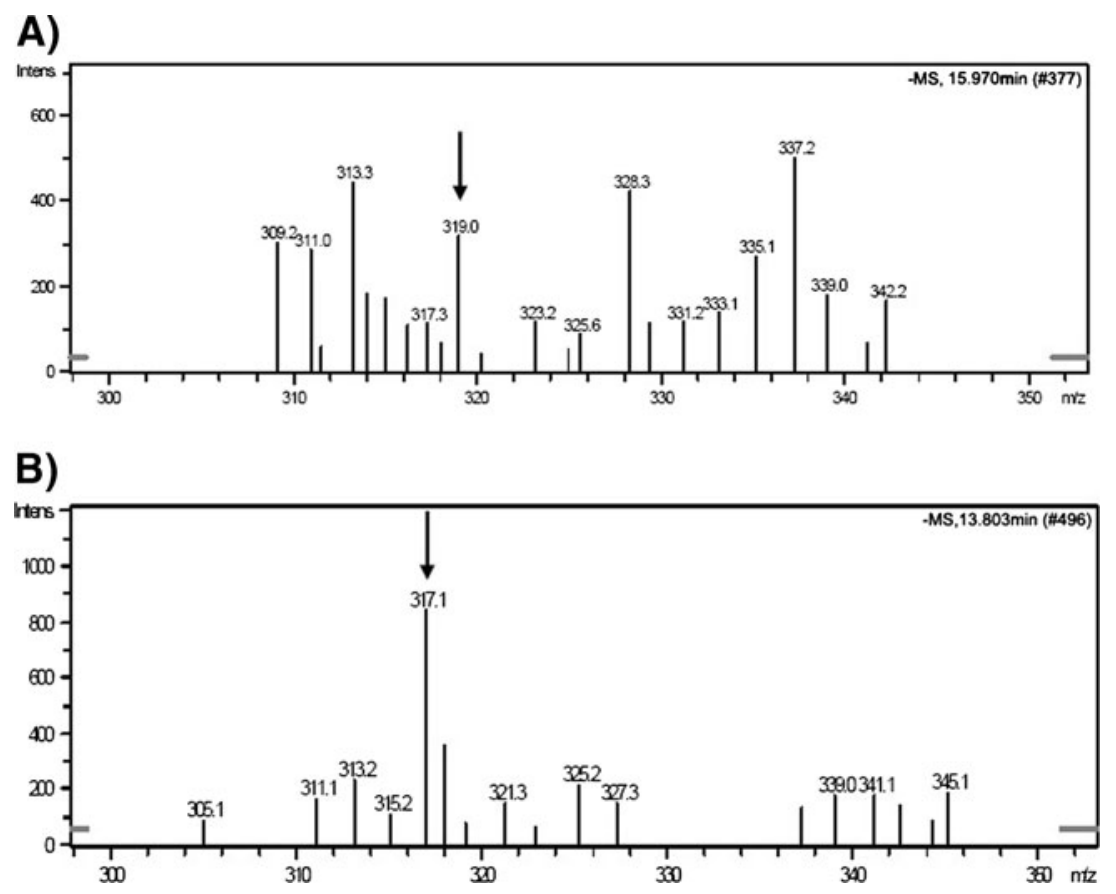

Application of the optimized UE-MISPE method for ZON and $\alpha$-ZOL extraction

The results of the analysis indicate that the neoplastically changed tissue samples collected from all patients contained zearalenone's estrogenic metabolite, $\alpha$-zearalenol, which bears a structural resemblance to natural estrogen, $17-\beta$ estradiol, and imitates its activity. Trace quantities of zearalenone were found in three samples. Zearalenone was not determined in the remaining four samples. All tissue samples contained various quantities of $\alpha$-zearalenol in the range of $0.1-1.7 \mu \mathrm{g} / \mathrm{g}$ tissue (Table 7, Fig. 5).

No correlations were determined between the $\alpha$ zearalenol content of the examined tissue and the clinical grade of cancer. Tumor consistency and the quantity of $\alpha$ zearalenol were correlated (the more compact the tissue, the smaller quantity of the metabolite was found).

The presence of $\alpha$-zearalenol and zearalenone in tissue affected by endometrial cancer was confirmed by the MS in the negative ionization module (Fig. 6). The presence of $\alpha$ zearalenol and zearalenone in neoplastically changed tissue from the tissue corpus of the uterus was confirmed by ions with $\mathrm{m} / \mathrm{z}$ ratios of 317.1 and 319.0 , respectively.

\section{Conclusions}

Highly efficient molecularly imprinted polymers (MIPCDHB) may be used as sorbents in solid-phase extraction for purification extracts of tissue and preconcentration $\mathrm{ZON}$ and $\alpha$-ZOL. The studied MIPs are characterized by high selectivity, and they shorten sample preparation time- the results of this experiment have shown that hexane deproteinization and degreasing of supernatants were redundant.

The presence of $\alpha$-zearalenol was determined in all uterus samples, while zearalenone was found in only three samples. No correlations were determined between the $\alpha$ zearalenol content of the studied tissue and the clinical stage of cancer. Tumor consistency and the quantity of $\alpha$ zearalenol were, however, correlated (the more compact the tissue, the smaller the quantity of the metabolite).

The results of this study indicate that in contrast to affinity adsorbents, molecularly imprinted polymers are suitable for purifying samples from the water-organic phase.

Ackowledgment The work was financially supported by the Ministry of Science and Higher Education (Warsaw, Poland) grant no. N N204 012038.

Open Access This article is distributed under the terms of the Creative Commons Attribution Noncommercial License which permits any noncommercial use, distribution, and reproduction in any medium, provided the original author(s) and source are credited.

\section{References}

1. Nugen S, Baeumner HJ (2008) Trends and opportunities in food pathogen detection. Anal Bioanal Chem 391:451-454

2. Zinedine A, Soriano JM, Moltó JC, Mańes J (2007) Review on the toxicity, occurrence, metabolism, detoxification, regulations and intake of zearalenone: an oestrogenic mycotoxin. Food Chem Toxicol 137:1-18 
3. Briones-Reyes D, Gómez-Martinez L, Cueva-Rolón R (2007) Zearalenone contamination in corn for human consumption in the state of Tlaxcala, Mexico. Food Chem 100:693-698

4. Othmen Z, El Golli E, Abid-Essefi S, Bacha H (2008) Cytotoxicity effects induced by zearalenone metabolites, $\alpha$-zearalenol and $\beta$ zearalenol, on cultured Vero cells. Toxicology 252:72-77

5. Berthiller F, Schuhmacher R, Gerhard A, Krska R (2009) Formation, determination and significance of masked and other conjugated mycotoxins. Anal Bioanal Chem 395:1243-1252

6. Vendl O, Berthiller F, Crews C, Krska R (2009) Simultaneous determination of deoxynivalenol, zearalenone, and their major masked metabolites in cereal-based food by LC-MS-MS. Anal Bioanal Chem 395:1347-1354

7. Minervini F, Giannoccaro A, Cavallini A, Visconti A (2005) Investigations on cellular proliferation induced by zearalenone and its derivatives in relation to the estrogenic parameters. Toxicol Lett 159:272-283

8. van Bennekom EO, Brouwer L, Laurant EHM, Hooijerink H, Nielen MWF (2002) Confirmatory analysis method for zeranol, its metabolites and related mycotoxins in urine by liquid chromatography-negative ion electrospray tandem mass spectrometry. Anal Chim Acta 473:151-160

9. Scippo ML, Van De Weerdt C, Willemsen P, Françoise RD, Muller M, Matrial JA, Maghuin-Rogister G (2002) Detection of illegal growth promoters in biological samples using receptor binding assays. Anal Chim Acta 473:135-141

10. Shier WT, Shier AC, Xie W, Mirocha CJ (2001) Structure-activity relationships for human estrogenic activity in zearalenone mycotoxins. Toxicon 39(9):1435-1438

11. Cavret S, Lecoeur S (2006) Fusariotoxin transfer in animal. Food Chem Toxicol 44:444-453

12. Malekinejad H, Colenbrander B, Fink-Gremmels J (2006) Hydroxysteroid dehydrogenases in bovine and porcine granulosa cells convert zearalenone into its hydroxylated metabolites $\alpha$ zearalenol and $\beta$-zearalenol. Vet Res Commun 30:445-453

13. Abbes S, Ouanes Z, Salah-Abbes JB, Abdel-Wahhab MA, Oueslati R, Bacha H (2007) Preventive role of aluminosilicate clay against induction of micronuclei and chromosome aberrations in bone-marrow cells of $\mathrm{BALB} / \mathrm{c}$ mice treated with zearalenone. Mut Res 631:85-92

14. Fink-Gremmels J, Malekinejad H (2007) Clinical effects and biochemical mechanisms associated with exposure to the mycoestrogen zearalenone. Ani Feed Sci Techno 137:326-341

15. Shin BS, Hong SH, Bulitta JB, Hwang SW, Kim HJ, Lee JB, Yang SD, Kim JE, Yoon HS, Kim do J, Yoo SD (2009) Disposition, oral bioavailability, and tissue distribution of zearalenone in rats at various dose levels. J Toxicol Environ Health A 72(21-22):1406-1411
16. Kolf-Clauw M, Ayouni F, Tardieu D, Guerre P (2007) HPLC assay of zearalenone and reduced metabolites in S9 fractions of duck liver. Revue Méd Vét 158(10):504-508

17. Coffey DS (2001) Similarities of prostate and breast cancer: evolution, diet, and estrogens. Urology 57(Supple. 4A):31-38

18. Hassen W, Ayed-Boussema I, Azqueta-Oscoz A, Lopez AC, Bacha H (2007) The role of oxidative stress in zearalenonemediated toxicity in Hep G2 cells: oxidative DNA damage, glutathione depletion and stress proteins induction. Toxicol 232:294-302

19. Salah-Abbès JB, Abbès S, Abdel-Wahhab M, Oueslati R (2010) Immunotoxicity of zearalenone in Balb/c mice in a high subchronic dosing study counteracted by Raphanus sativus extract. Immunopharmacol Immunotoxicol 32(4):628-636

20. Minervini F, Dell'Aquila ME, Maritato F, Minoia P, Visconti A (2001) Toxic effects of the mycotoxin zearalenone and its derivatives on in vitro maturation of bovine oocytes and $17 \beta$ estradiol levels in mural granulosa cell cultures. Toxicol Vitro $15: 489-495$

21. Urraca JL, Marazuela MD, Merino ER, Orellana G, MorenoBondi MC (2006) Molecularly imprinted polymers with a streamlined mimic for zearalenone analysis. J Chromatogr 1116:127-134

22. Navarro-Villoslada F, Urraca JL, Moreno-Bondi MC, Orellana G (2007) Zearalenone sensing with molecularly imprinted polymers and tailored fluorescent probes. Sensors and Actuators B 121: $67-73$

23. Urraca JL, Marazuela MD, Moreno-Bondi MC (2006) Molecularly imprinted polymers applied to the clean-up of zearalenone and $\alpha$-zearalenol from cereal and swine feed sample extract. Anal Bioanal Chem 385:1155-1161

24. Rodriguez E, Navarro-Villoslada F, Moreno-Bondi MC, Marazuela MD (2010) Optimization of a pressurized liquid extraction method by experimental design methodologies for the determination of fluoroquinolone residues in infant foods by liquid chromatography. J Chromatogr 1217:605-614

25. Ričanyová J, Gadzała-Kopciuch R, Reiffová K, Buszewski B (2009) Estrogens and their analytics by hyphenated separation techniques. Crit Rev Anal Chem 39(1):13-31

26. Buszewski B, Ričanyová J, Gadzała-Kopciuch R, Szumski M (2010) Supramolecular recognition of estrogens via molecularly imprinted polymers. Anal Bioanal Chem 397:2977-2986

27. Lucci P, Derrien D, Alix F, Pérollier C, Bayoudh S (2010) Molecularly imprinted polymer solid-phase extraction for detection of zearalenone in cereal sample extracts. Anal Chim Acta 672:15-19 